\title{
Molecular approach (PCR-DGGE) to diet analysis in young Antarctic krill Euphausia superba
}

\author{
Daniel L. Martin ${ }^{1,3}$, Robin M. Ross ${ }^{1}$, Langdon B. Quetin ${ }^{1}$, Alison E. Murray ${ }^{2, *}$ \\ ${ }^{1}$ Marine Science Institute, University of California, Santa Barbara, California 93106, USA \\ ${ }^{2}$ Earth and Ecosystem Sciences, Desert Research Institute, 2215 Raggio Parkway, Reno, Nevada 89512, USA \\ ${ }^{3}$ Present address: Department of Biological Sciences, LSCB-124, University of South Alabama, Mobile, Alabama 36688, USA
}

\begin{abstract}
Antarctic krill Euphausia superba Dana comprise a key component of the Southern Ocean food web, yet despite decades of research, questions concerning the regional, seasonal and ontogenetic differences in their diet remain. All current methods used to characterize krill diet have limitations for identifying the full complement of the diet. Using DNA as a marker molecule, our goal in this study has been to evaluate the efficacy of a PCR-DGGE (denaturing gradient gel electrophoresis) approach targeting the 18S rDNA gene to discriminate among diet constituents in gut and fecal pellet samples from young Antarctic krill relative to their feeding environment - the seawater and sea ice microbial community. We conducted 2 laboratory-based feeding experiments with known food items and 3 field samplings of both the krill and their feeding environment. Sequenced PCRDGGE phylotypes from laboratory trials clearly distinguished diatom and copepod prey, while in situ feeding analyses revealed that a broad diversity of taxa were ingested, including diatoms (Bacillariophyta, the most prevalent group detected), dinoflagellates, cryptomonads, prasinophytes, ciliates, cercozoans, choanoflagellates, turbellarians and (possibly) sponge larvae. Band image analyses allowed environmental and diet phylotypes to be matched. On average, $32 \%$ of those from the environment were present in the diet; conversely, of the phylotypes detected in the diet, an average of $59 \%$ were in common with the environment. Changes in environmental phylotypes among sampling dates were reflected by similar changes in the krill diet as potential prey diversity (richness) decreased during a phytoplankton bloom.
\end{abstract}

KEY WORDS: Antarctic krill · Euphausia superba $\cdot$ Diet · DGGE $\cdot 18 \mathrm{~S} \mathrm{rDNA} \cdot$ Sea ice microbial community $\cdot$ Omnivory

\section{INTRODUCTION}

Antarctic krill Euphausia superba Dana serve as both an important grazer (Walsh et al. 2001) and a critical prey item for the reproductive success of seals, seabirds and whales in the Southern Ocean (Croxall et al. 1999). Although generally characterized as herbivorous, E. superba is clearly omnivorous. Around South Georgia, one of the South Shetland Islands northeast of the Antarctic Peninsula, Antarctic krill are dependent on heterotrophic food sources, including small (1 to $3 \mathrm{~mm}$ ) copepods (Atkinson \& Snÿder 1997). However, west of the Antarctic Peninsula, where the phytoplankton biomass is higher than around South Georgia and large copepods dominate (Ross et al. 1996), growth (secondary production) in krill is correlated with phytoplankton food sources (Ross et al. 2000). For larval krill, in which the feeding ecology is less well known than that of the adults, overwinter feeding and survival is suspected to rely on the complex assemblage of autotrophs (and possibly heterotrophs) comprising the sea ice microbial community (Frazer et al. 2002 and references therein).

All the current methods used to characterize the krill diet have limitations for identifying the taxonomic complexity of the diet, varying in both degree of specificity and sensitivity. These methods have various constraints; for example microscopy is limited to 
undigested hard parts such as copepod mandibles, diatom frustules, or tintinnid loricae (Hopkins \& Torres 1989), gut fluorescence detects only algal pigments (Ross et al. 2004), and monoclonal antibodies target specific species of interest (Haberman et al. 2002). Biomarker methods analyzing fatty acid and stable isotope composition of krill have been found to target a wider variety of diet components, but are limited in the taxonomic resolution they provide (Frazer 1996, Alonzo et al. 2003). PCR-based molecular methods for detecting DNA offer promising new avenues for diet analysis (Symondson 2002), and are currently being used in marine systems (Jarman et al. 2002, Nejstgaard et al. 2003). A distinct advantage of using a molecule such as DNA to detect diet diversity is that all potential prey items have DNA, and thus detection of a dietary item will depend more on sensitivity to the molecular signal than on such group-specific biases as those mentioned above. Although a number of studies have utilized some form of DNA detection of prey in predator diets (e.g. Zaidi et al. 1999, Rosel \& Kocher 2002, Jarman et al. 2004), molecular approaches have seldom been applied to marine crustaceans (Nejstgaard et al. 2003).

The choice of indicator molecule or gene fragment is a central issue to consider when molecular signatures are used to describe prey. Although there are a few molecules to choose from that would be informative in terms of phylogenetic accuracy in prey identification (e.g. organellar 16S rDNA or Cytochrome C, nuclear ribosomal internal transcribed spacer, 28S rRNA), the largest amount of eukaryotic diversity data exists for the small subunit ribosomal RNA gene (18S rDNA). Surveys of picoplankton 18S rDNA in marine environments in recent years have revealed extensive phylogenetic diversity and novel lineages (López-Garcia et al. 2001, Moon-van der Staay et al. 2001). In addition to constructing and sequencing clone libraries to access 18S rRNA sequence diversity, denaturing gradient gel electrophoresis (DGGE), a method that separates PCR amplicons based on their melting points along a denaturant gradient within an electrophoresed gel matrix, can be used to profile sequence heterogeneity in a complex mixture. DGGE has long been used in studies of diversity in natural microbial assemblages (e.g. Muyzer et al. 1993, Murray et al. 1996), to characterize gut flora (Simpson et al. 1999, Regensbogenova et al. 2004), and recently to characterize eukaryote community diversity (van Hannen et al. 1998, Diez et al. 2001, Gast et al. 2004). Detecting molecular diversity in a zooplankter's diet is similar to investigating diversity of the micro- or nanoplankton itself, although the potential for PCR inhibition, or signal masking by the host which could confound the diet signal, are issues that remain to be investigated.
In this study we conducted 2 laboratory-based feeding experiments with known food items, and 3 field samplings of a euphausiid grazer and its possible food sources. Our goal was to evaluate the efficacy of a PCR-DGGE approach to discriminate between diet constituents in gut and fecal pellet samples from young Antarctic krill Euphausia superba relative to the eukaryal diversity present in the feeding environment (seawater and the sea ice microbial community). As part of this effort, we sequenced a number of bands (phylotypes) separated by PCR-DGGE from both the environment and the diet; in addition, the sequence of the 18S rDNA gene was determined for this euphausiid species.

\section{MATERIALS AND METHODS}

Study site. This study was conducted with Euphausia superba collected from coastal waters (Hero Inlet or Arthur Harbor) south of Anvers Island $\left(64^{\circ} \mathrm{S}, 64^{\circ} \mathrm{W}\right)$, west of the Antarctic Peninsula. Laboratory-based feeding experiments were conducted at Palmer Station (USA), located on Anvers Island. In situ feeding (ISF) experiments were conducted in the coastal waters on 3 occasions in 2002 (ISF-1 on 3 November, ISF-2 on 14 November and ISF-3 on 12 December) as the environmental conditions changed rapidly during the austral spring of 2002. Sea ice in the area, consisting mostly of 'old' floes colored by the sea ice-associated microorganisms and melting in the springtime waters, was transient between ISF-1 and ISF-2, and absent from the region by December. Water column chlorophyll a concentrations integrated above the $1 \%$ light level were about $75 \mathrm{mg} \mathrm{m}^{-2}$ in early November, rapidly increased to a peak (bloom) value near $200 \mathrm{mg} \mathrm{m}^{-2}$ by mid November, and then decreased to relatively low values $\left(<50 \mathrm{mg} \mathrm{m}^{-2}\right)$ from late November through mid December (M. Vernet pers. comm.).

Laboratory feeding. We ran 2 experiments to validate the use of DGGE in distinguishing diet items in krill with different feeding histories. An Antarctic diatom culture and a mix of freshly collected copepods were used as the 2 food sources. Krill for both experiments were collected by SCUBA divers during the austral spring of 2002 from under ice floes alongshore at Palmer Station using small $(10 \mathrm{~cm} \times 10 \mathrm{~cm})$ hand nets and held in a flow-through seawater system under ambient conditions of food and temperature until used. In the first experiment, 15 to 20 late larval and early juvenile krill (size = 12 to $19 \mathrm{~mm}$ total length, TL) were starved $24 \mathrm{~h}$ in $0.2 \mu \mathrm{m}$ filtered seawater and then allowed to feed for $3 \mathrm{~h}$ on the diatom Fragilariopsis curta (Van Heurck) Hustedt: inoculum purchased from Bigelow Laboratory under the synonym Nitzschia 
curta (Van Heurck) Hasle. Several individuals were then removed and immediately frozen at $-70^{\circ} \mathrm{C}$ for gut sample analysis, and the rest rinsed twice and held in a jar of filtered seawater to retain fecal pellets. After $1 \mathrm{~h}$, fecal pellets were collected for use as a second source of diet samples for DGGE analysis; aliquots of the algal culture were filtered onto $0.8 \mu \mathrm{m}$ polycarbonate filters, while fecal pellet samples were filtered onto 5- $\mu \mathrm{m}$ filters; the filters were then placed in sterile tubes and immersed in a sucrose-based buffer (SLB, 40 mM EDTA $\mathrm{pH} 8.0,500 \mu \mathrm{M}$ Tris $\mathrm{pH} 8.3,0.73 \mathrm{M}$ sucrose). We used 2 approaches to acquire foregut samples. Initially ( $F$. curta experiment), using a sterile technique, the entire foregut was excised from frozen individuals lying on a chilled plate. In all subsequent experiments the semifrozen contents were removed from the surrounding foregut, thereby avoiding most krill tissue in order to minimize complications with the molecular analyses. Samples were then placed in sterile $1.5 \mathrm{ml}$ tubes and SLB added. All samples were stored at $-70^{\circ} \mathrm{C}$ until DNA extraction. The same feeding and sample collection protocol was used in the second experiment in which juvenile and subadult krill were fed a mixture of small copepods collected $\sim 2 \mathrm{~h}$ earlier from surface waters $(0$ to $20 \mathrm{~m}$ ) near Palmer Station on 2 January 2003. Preceding the experiment, subsamples of the copepod catch were frozen in aliquots of SLB at $-70^{\circ} \mathrm{C}$ for subsequent DGGE analysis. Any large (>2 mm) individuals were also removed from the catch prior to the experiment. Gut and fecal pellet samples were processed as described above.

In situ feeding. We collected 3 sets of in situ feeding samples to investigate DGGE as a method for examining differences between available prey and consumed prey under different field conditions. Krill and their potential food items were collected mid-day from sea ice-dominated waters in 2 experiments (ISF-1 and 2), and from ice-free water in the last experiment. Late larval (Furcilia 6) and early juvenile stage krill were collected by divers from waters near Palmer Station as described above from aggregations of individuals feeding in sea ice pockets and on the under-surface of the sea ice floes. During the short swim to shore with krill in the hand net $(<3 \mathrm{~min})$, the flow of water through the net kept the krill pressed to the back of the net, preventing net feeding. Subsequently, they were either frozen immediately for subsequent gut sampling or used to generate fecal pellets. Pieces of sea ice from the same floes, and seawater samples from $1 \mathrm{~m}$ below the sea ice, were collected by divers as potential sources of prey items. Sea ice (allowed to melt at $4^{\circ} \mathrm{C}$ over $24 \mathrm{~h}$ ) and seawater samples accompanying each experiment (1 1 each) were filtered and frozen as described for the algal cultures above. In ISF-3, juvenile and sub-adult krill were collected on 12 December in sea ice-free waters in the vicinity of Palmer Station. The krill school at $20 \mathrm{~m}$ depth was located with an acoustic transducer (Biosonics Model 102) and sampled with a 1-m ring net. We used a $333 \mu \mathrm{m}$ mesh net, short tow and rapid processing to minimize or prevent net feeding. We estimated the time from when the krill were caught to the end of processing as $<5 \mathrm{~min}$. A seawater sample was collected from the same depth as the targeted school with a Niskin bottle (General Oceanics).

Abdominal muscle tissue from an adult Euphausia superba was excised and stored in SLB at $-70^{\circ} \mathrm{C}$ for DNA extraction and sequencing of the $18 \mathrm{~S}$ rDNA gene.

DNA extraction. Genomic DNA was extracted from all samples according to the method described in Massana et al. (1997), except for large tissue masses (i.e. krill muscle and whole copepods) where sterile glass beads $(0.1 \mathrm{~mm}$ diameter) were added to the samples and then bead-beaten 1 min to disrupt cells. Cells in all samples were then lysed by the addition of (at final concentration) sodium dodecyl sulfate $(1 \%)$, and proteinase $\mathrm{K}\left(5 \mathrm{mg} \mathrm{ml}^{-1}\right)$ and incubating at $55^{\circ} \mathrm{C}$ for $1.5 \mathrm{~h}$. DNA was purified following standard phenol:chloroform purification using (1) ethanol precipitation followed by suspension in TE $(10 \mathrm{mM}$ Tris- $\mathrm{HCl} \mathrm{pH} 8.0$, 0.1 mM EDTA pH 8.0), or (2) centrifugal concentration (Centricon-100, Millipore) followed by $2 \times 1 \mathrm{ml}$ washes in TE, and final concentration to $\sim 20 \mu$ l. The DNA yield was quantified using PicoGreen (Molecular Probes, as per manufacturer's instructions) on a fluorometer (Labsystems Fluoroskan Ascent), then stored at -20 or $-70^{\circ} \mathrm{C}$ until analyzed.

PCR. The extracted DNA was used as a template to amplify a $\sim 240$ bp region coding for the eukaryal 18S rRNA gene using eukaryote-specific $960 \mathrm{bF}-\mathrm{GC}$ and universal 1200R (Gast et al. 2004) oligonucleotide primers. Most reactions were performed in $100 \mu \mathrm{l}$ volumes with the addition of (at final concentration) deoxynucleoside triphosphates (0.2 $\mathrm{mM}$ each), $\mathrm{MgCl}_{2}$ (3.5 mM), primers (1.0 $\mu \mathrm{M}$ each), Taq DNA polymerase (0.5 U) (Eppendorf or AmplitaqGold, ABI), PCR buffer (1×) supplied with the Taq, and $\sim 10 \mathrm{ng}$ of template DNA. Samples were amplified (ThermoHybaid PCR Express; 28 cycles) following Gast et al. (2004). Successful amplification products were quantified using the Pico-Green method following DNA precipitation in ethanol. Amplifications of samples with DNA concentrations below picogreen detection limits (some gut samples) were run for a total of 35 cycles.

DGGE. Purified nucleic acid samples were separated by electrophoresis using a BioRad DCode DGGE apparatus. Briefly, $8 \%$ polyacrylimide (acrylamide:bisacrylamide 37.5:1), $1 \mathrm{~mm}$ thick gels with a linear denaturant gradient of 35 to $45 \%$ (where $100 \%$ denaturant $=40 \%$ 
deionized formamide and $7 \mathrm{M}$ urea), were run for $10 \mathrm{~h}$ at $90 \mathrm{~V}$ in a $60^{\circ} \mathrm{C}$ bath of $1 \times$ TAE buffer $(40 \mathrm{mM}$ Tris, $40 \mathrm{mM}$ acetic acid, $1 \mathrm{mM}$ EDTA, $\mathrm{pH}$ 7.4). Gels were then stained 15 min in SybrGold (Molecular Probes), UV-illuminated, and photographed. Optimal denaturant gradient and DNA amounts for comparative analysis were determined empirically; DNA amount varied by sample type and complexity (100 to $600 \mathrm{ng}$ per lane for gut, fecal pellet, sea ice or seawater).

DNA sequencing. Bands with unique migration points (and several with identical melting points in adjacent lanes or different gels) were excised from the denaturing gradient gels for DNA sequence analysis. Acrylamide slices excised with a sterile scalpel were suspended in $200 \mu \mathrm{l}$ of sterile water with an aliquot of glass beads, and bead-beaten for $1 \mathrm{~min}$ to disrupt the gel fragment. This solution was stored overnight at $4^{\circ} \mathrm{C}$ before using a $0.5 \mu \mathrm{l}$ aliquot to re-amplify (PCR) the isolated product with the original primer set (less the primer GC-clamp sequence) and the same amplification conditions described previously. PCR products were verified by agarose gel electrophoresis, then purified with Qiaquick columns (Qiagen). DNA was sequenced bidirectionally with the 960F/1200R primer set on an ABI 3730 genetic analyzer, then sequences were assembled (Sequencher, GeneCodes) and compared to the 'nt' and 'env_nt' nucleotide databases provided by the NCBI using BLAST (Altschul et al. 1997) run locally. Taxonomic information was accessed through the NCBI taxonomy database. The trophic status of phylotypes (18S rRNA sequence types) with high sequence identity to characterized organisms were designated as either autotrophic or heterotrophic based on the predominant trophic mode for that taxa.

In some cases (16 of 35), co-migrating bands (with putatively identical sequences) were sequenced from different sample types and experiments. In nearly all cases (15 of 16), identical sequences were found, and 1 sequence was chosen as the 'type' sequence for that band. Despite this high degree of reproducibility, not all bands excised resulted in high quality sequences.

The 18S rRNA gene from the abdominal muscle of an adult Euphausia superba sample was PCRamplified with Euk1A (Sogin \& Gunderson 1987) and Univ1492 (Kane et al. 1993), then bidirectionally sequenced with Euk1A, Euk326F (reverse and complement from Euk309R, Lim et al. 1993), Univ533F (modification from Weisburg et al. 1991), Euk960F and Univ1200R (Gast et al. 2004), Euk516R (Amann et al. 1995) and Univ1492R. The GenBank Accession No. for the E. superba 18S rDNA sequence is DQ201509 (see Table 1 for accession numbers of unique DGGE phylotypes).

DGGE band image analysis. Images of DGGE gels were processed using GelComparII (Applied Maths) to facilitate band (phylotype) detection and alignment within each gel, allowing us to then determine the number of bands with unique melting points (i.e. phylotype richness). Phylotype profiles (phylotypes in each lane) were compared by pairwise similarity using Sörensen's index $\left(C_{s}\right) ; C_{s}=2 \times j /(a+b)$, where $j$ is the number of common phylotypes, $a$ is the number of phylotypes in Lane $\mathrm{a}$, and $b$ is the number of phylotypes in Lane b (Murray et al. 1996, adopted from Magurran 1988). In DGGE lanes where the krill phylotype appeared, this phylotype was not counted in richness or similarity measures. Also, in addition to considering pairwise similarity between individual DGGE lanes, the sum of phylotypes with unique melting points in gut plus fecal pellets profiles, and in sea ice plus seawater profiles were calculated to represent the complete diet and complete environment food sources, respectively.

\section{RESULTS}

\section{Laboratory feeding experiments}

Starved krill fed Fragilariopsis curta. The PCRDGGE results indicated that algal and krill rDNA phylotypes migrated to different positions in a 35 to $45 \%$ denaturing gradient gel, and that solely algal and krill rDNA sequences were detected in krill diet samples. In the cultured algal sample (food source), 2 bands were present that co-migrated with 2 bands in the fecal pellet sample (Fig. 1a); all 4 were sequenced and found to be identical over the 234 base region (AntEuk13-24, Table 1). There were also 2 bands present in the whole foregut sample that matched a region of the Antarctic krill 18S rRNA gene we sequenced from abdominal muscle (100\% match over 250 bases; AntEuk13-5: Table 1).

Starved krill fed a mix of wild copepods. A total of 16 bands were found in the wild copepod mixture (Fig. 1b), 5 of which had co-migrating bands in gut and fecal pellet profiles. Additionally, a large copepod removed prior to the feeding trial and processed separately resulted in a single band (Fig. 1b, Lane 2), indicating that different crustacean 18S rDNA sequences can be detected with this approach, and that they can be detected in krill gut and fecal pellet samples. Of the 13 bands sequenced from this experiment, 7 produced unique sequences. Several bands with the same sequence, yet varying in length at the 5 '- and 3 '-ends as a result of varying sequence quality (210 to 237 bases), matched AntEuk16-8, an environmental copepod clone, but migrated to different positions in the gel (Fig. 1b, Lane 1, lower 4 numbered bands). Image analysis revealed that 5 of 8 bands in the diet samples 

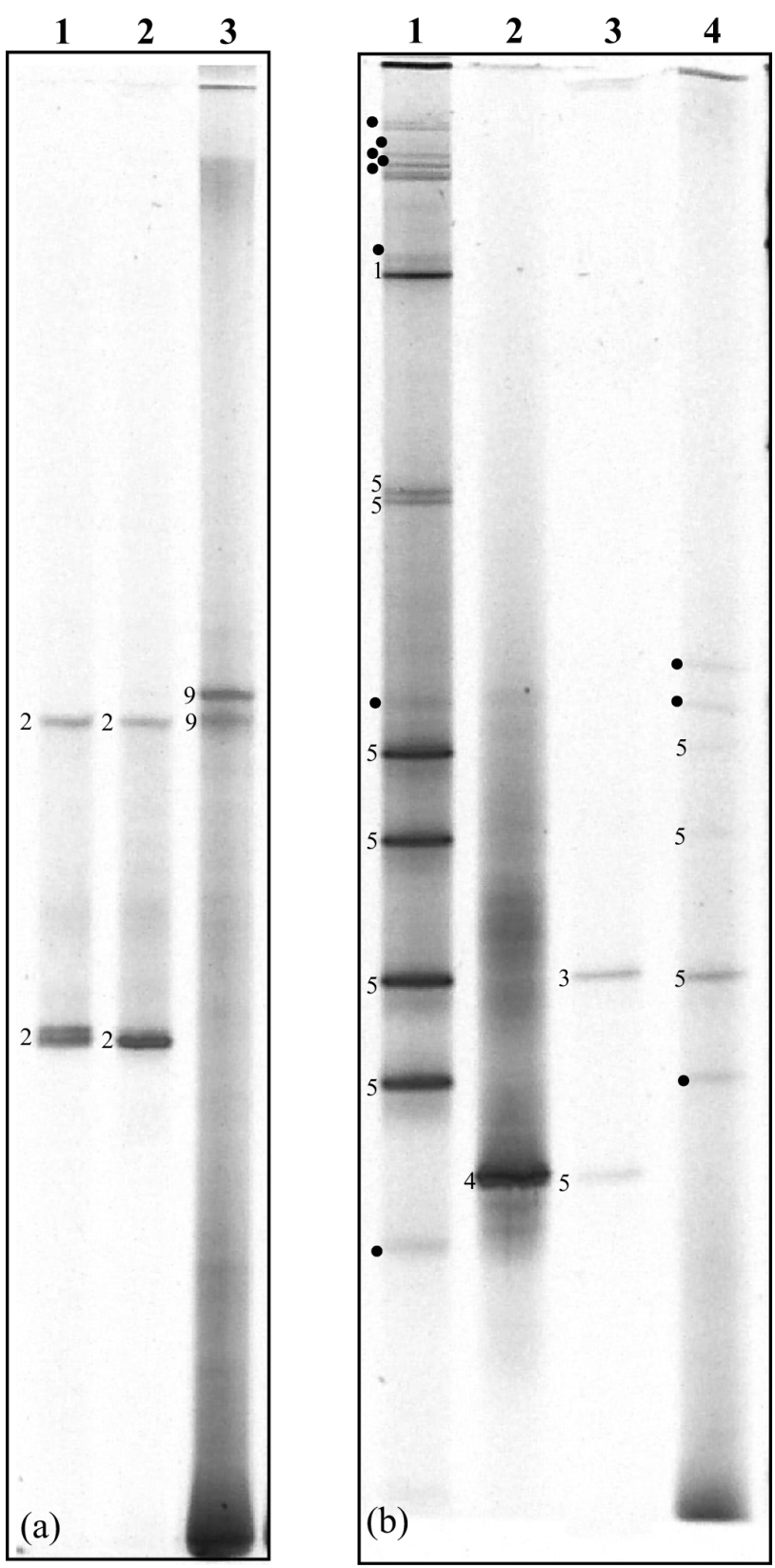

Fig. 1. DGGE images and sequenced phylotypes from laboratory feeding trials with Euphausia superba. Starved krill were fed either (a) diatom diet (Lane 1: Fragilariopsis curta; 2: krill fecal pellets; 3: krill gut contents) or (b) copepod diet (Lane 1: mixture of wild copepods; 2: a large unique species of copepod not in lane 1; 3: krill gut contents; 4: krill fecal pellets). Numbers are codes for bands excised and sequenced for phylotype analysis (see Table 1, Column 1). Dots indicate gel position of bands not sequenced

were in common with those from the copepod mixture; 2 other phylotypes (AntEuk17-13 and AntEuk17-7; Table 1) matched a gastropod (96\% identity over 212 bases) and an apicomplexan (99\% over 131 bases) sequence, respectively.

\section{In situ feeding and environmental sampling}

ISF-1: Under sea ice, early bloom conditions. Phylotype profiles from the 3 November field samples were the richest in terms of diversity, with 41 phylotypes from the environment and 49 overall (Table 2, Fig. 2a). Sea ice and seawater phylotype profiles were quite different $\left(C_{s}=0.33\right)$. Of the 41 environment phylotypes, 11 $(27 \%)$ were in common with the diet samples. The gut sample was more diverse and potentially more informative than the fecal sample, although the majority of detected phylotypes were different $\left(C_{S}=0.35\right)$. Of the 19 bands detected in the fecal and gut samples, those in common with sea ice and seawater phylotypes (11) represented $58 \%$ of the diet. Phylotype sequence analyses revealed a diversity of autotrophs dominated numerically by diatom-related phylotypes in both the environment and diet, although several heterotrophs (e.g. Ciliophora, Cercozoa, Turbellaria) were also present in these samples (Table 1, Fig. 2a).

ISF-2: Under sea ice, peak bloom conditions. Timing of the second experiment on 14 November was coincident with a significant algal bloom comprised in part of diatoms Thalassiosira spp. and Chaetoceros sp., and the prymnesiophyte Phaeocystis sp. (identified by light microscopy, W. Kozlowski pers. comm.). Phylotype richness was the lowest of the 3 periods examined, with a combined total of 14 bands with different melting points appearing in sea ice and seawater (Fig. 2b), and a higher phylotype profile $C_{s}$ of 0.60 (Table 2) than ISF-1. The reduced richness in the environment was reflected in the diet, with only 7 phylotypes detected in the combined fecal and gut samples. In this case, 5 of the 7 diet phylotypes $(71 \%)$ were in common with bands in the environmental samples. The same 5 bands represented $36 \%$ of the environmental pool of phylotypes. The gut profile was again more diverse and not very similar $\left(C_{s}=0.44\right)$ to the fecal profile. Sequence analysis of excised bands revealed that diatom-affiliated sequences dominated the phylotype diversity in both the diet and the environment, although heterotroph-related taxa were found in each phylotype profile (e.g. Ciliophora, Turbellaria: Table 1, Fig. 2b).

ISF-3: Open water, post bloom conditions. On $12 \mathrm{De}-$ cember, 18 environmental phylotypes were detected in the open water sample (Table 2, Fig. 2c), which in comparison to ISF-1 and ISF-2 suggests a moderately rich eukaryal assemblage. Of these 18, 6 (33\%) were in common with those in the diet samples. Phylotype richness of the diet samples was high (13 bands in gut plus fecal samples) relative to the environment, with $46 \%$ of the diet phylotypes ( 6 bands) in common with the environment. Diet samples were derived from juvenile (ca. $19 \mathrm{~mm} \mathrm{TL}$ ) and small adult (ca. $33 \mathrm{~mm} \mathrm{TL}$ ) size classes 
collected at the same time, although gut composition was quite different between these individuals $\left(C_{s}=\right.$ 0.29 ). Phylotype profiles from the juveniles' $(\mathrm{n}=2$ individuals, pooled to partly compensate for the volume of the adult gut) foreguts more closely matched the seawater ( 5 of 6 bands) than the adult ( $\mathrm{n}=1$ individual; 3 of 10 bands) profile. Sequenced phylotypes in this period, as in ISF-1 and 2, continued to show dominance of Fragilariopsis curta-related sequences (AntEuk13-24) in both the diet and environment. Heterotrophs were again common in the environment (e.g. choanoflagellates, Cercozoa, Porifera), 1 of which co-migrated with a band in the diet (AntEuk20-29; Table 1, Fig. 2c). The same phylotype was sequenced in ISF-1.

Table 1. Taxonomic relatedness of excised DGGE phylotypes for laboratory and in situ feeding samples of Euphausia superba. Trophic mode: $\mathrm{A}=$ autotroph, $\mathrm{H}$ = heterotroph. Top BLAST hit listed from either 'nt' or 'env_nt' database. Band ID: sequenced band identity. For sequences with multiple tied matches of $<100 \%$ identity, only 1 representative is listed

\begin{tabular}{|c|c|c|c|c|c|c|c|}
\hline $\begin{array}{l}\text { Band code } \\
\text { (Figs. } 1 \& 2 \text { ) }\end{array}$ & Band ID & $\begin{array}{c}\text { NCBI } \\
\text { Accession } \\
\text { No. }\end{array}$ & $\begin{array}{l}\text { Sequence } \\
\text { length } \\
\text { (bp) }\end{array}$ & $\begin{array}{l}\% \text { Sequence } \\
\text { identity of } \\
\text { closest relative }\end{array}$ & Closest relative & $\begin{array}{l}\text { Closest relative } \operatorname{Tr} \\
\text { higher taxon }\end{array}$ & $\begin{array}{r}\text { Trophic } \\
\text { mode }\end{array}$ \\
\hline \multicolumn{8}{|c|}{ Laboratory feeding experiments } \\
\hline 1 & AntEuk17-13 & DQ201510 & 224 & 98 & Babesia caballi & Apicomplexa & \\
\hline 2 & AntEuk13-24 & DQ201511 & 234 & 100 & Fragilariopsis curta ${ }^{\mathrm{C}}$ & Bacillariophyta & \\
\hline 3 & AntEuk17-7 & DQ201512 & 211 & 96 & Umbraculum umbraculum & Gastropoda & \\
\hline 4 & AntEuk16-19 & DQ201513 & 230 & 100 & Neocalanus cristatus & Crustacea & \\
\hline 5 & AntEuk16-8 & DQ201514 & 230 & 97 & Uncultured copepod isolate ${ }^{a}$ & Crustacea & \\
\hline 6 & AntEuk16-13 & DQ201515 & 231 & 91 & Uncultured copepod isolate ${ }^{a}$ & Crustacea & \\
\hline 7 & AntEuk16-14 & DQ201516 & 231 & 95 & Uncultured copepod isolate ${ }^{a}$ & Crustacea & \\
\hline 8 & AntEuk17-17 & DQ201517 & 237 & 97 & Uncultured copepod isolate ${ }^{a}$ & Crustacea & \\
\hline 9 & AntEuk13-5 & DQ201509 ${ }^{b}$ & 250 & 100 & Euphausia superba & Crustacea & \\
\hline \multicolumn{8}{|c|}{ In situ feeding and environmental sampling } \\
\hline 10 & AntEuk13-109 & DQ201518 & 231 & 93 & Strobilidium caudatum & Ciliophora & $\mathrm{H}$ \\
\hline 11 & AntEuk20-21 & DQ201519 & 228 & 96 & Paranophrys magna & Ciliophora & $\mathrm{H}$ \\
\hline 12 & AntEuk13-43 & DQ201520 & 232 & 99 & Scrippsiella trochoidea & Dinophyceae & A \\
\hline 13 & AntEuk20-12 & DQ201521 & 232 & 99 & Cryptoperidiniopsoid sp. & Dinophyceae & $\mathrm{H}$ \\
\hline 14 & AntEuk20-25 & DQ201522 & 228 & 97 & Geminigera cryophila & Cryptomonadaceae & A \\
\hline 15 & AntEuk13-94 & DQ201523 & 228 & 97 & Plagioselmis prolonga & Cryptomonadaceae & A \\
\hline 16 & AntEuk13-117 & DQ201524 & 224 & 97 & Phaeocystis pouchetii & Prymnesiophyceae & A \\
\hline 17 & AntEuk20-16 & DQ201525 & 229 & 99 & Bathycoccus prasinos & Prasinophyceae & A \\
\hline 18 & AntEuk13-96 & DQ201526 & 234 & 98 & Uncultured prasinophyte clone ${ }^{\mathrm{a}}$ & Prasinophyceae & A \\
\hline 19 & AntEuk20-10 & DQ201527 & 239 & 97 & Chaetoceros sp. & Bacillariophyta & A \\
\hline 20 & AntEuk13-40 & DQ201528 & 243 & 99 & Eucampia antarctica & Bacillariophyta & A \\
\hline 21 & AntEuk20-17 & DQ201529 & 233 & 96 & Haslea crucigera & Bacillariophyta & $\mathrm{A}$ \\
\hline 22 & AntEuk13-29 & DQ201530 & 235 & 97 & Navicula diserta & Bacillariophyta & $\mathrm{A}$ \\
\hline 23 & AntEuk13-118 & DQ201531 & 242 & 98 & Porosira pseudodenticulata & Bacillariophyta & A \\
\hline 24 & AntEuk20-14 & DQ201532 & 234 & 98 & Porosira pseudodenticulata & Bacillariophyta & A \\
\hline 2 & AntEuk13-24 & DQ201511 & 234 & 100 & Fragilariopsis curta $^{\mathrm{c}}$ & Bacillariophyta & A \\
\hline 25 & AntEuk13-107 & DQ201533 & 234 & 100 & Thalassiosira pseudonana ${ }^{\mathrm{d}}$ & Bacillariophyta & A \\
\hline 26 & AntEuk20-22 & DQ201534 & 234 & 94 & Thalassiosira pseudonana & Bacillariophyta & A \\
\hline 27 & AntEuk13-100 & DQ201535 & 168 & 94 & Cercozoan sp. & Cercozoa & $\mathrm{H}$ \\
\hline 28 & AntEuk13-28 & DQ201536 & 245 & 94 & Uncultured cercozoan clone ${ }^{a}$ & Cercozoa & $\mathrm{H}$ \\
\hline 29 & AntEuk13-95 & DQ201537 & 170 & 99 & Uncultured choanoflagellate $^{a}$ & Choanoflagellida & $\mathrm{H}$ \\
\hline 30 & AntEuk20-29 & DQ201538 & 234 & 93 & Scypha raphanus & Porifera & $\mathrm{H}$ \\
\hline 31 & AntEuk20-1 & DQ201539 & 228 & 93 & Uncultivated turbellarian $^{a}$ & Turbellaria & $\mathrm{H}$ \\
\hline 32 & AntEuk13-26 & DQ201540 & 246 & 98 & Chaetopleura apiculata & Polyplacophora & $\mathrm{H}$ \\
\hline 33 & AntEuk13-114 & DQ201541 & 230 & 98 & Eucalanus inermis & Crustacea & $\mathrm{H}$ \\
\hline 9 & AntEuk13-5 & DQ201509 & 250 & 100 & Euphausia superba & Crustacea & \\
\hline 34 & AntEuk13-84 & DQ201542 & 228 & 99 & Uncultured eukaryote clone ${ }^{a}$ & Eukaryota & $?$ \\
\hline 35 & AntEuk20-15 & DQ201543 & 234 & 98 & Uncultured eukaryote isolate $^{a}$ & Eukaryota & $\mathrm{A}^{\mathrm{e}}$ \\
\hline \multicolumn{8}{|c|}{ a'env_nt' database } \\
\hline \multicolumn{8}{|c|}{ 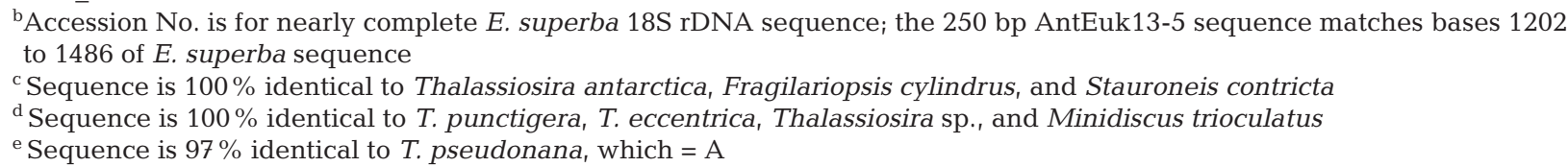 } \\
\hline
\end{tabular}




\section{DISCUSSION}

The results suggest that PCR-DGGE is efficient in detecting and distinguishing many diverse diet items of Euphausia superba. At least 16 autotroph-related phylotypes and 10 heterotroph-related phylotypes were identified by DNA sequence analysis. The diet (foregut plus fecal phylotypes) reflected the food source in laboratory feeding experiments, and when investigated in naturally feeding juvenile krill, an average of $59 \%$ ( $n=$ $3, \mathrm{SD}=12.6$ ) of the diet phylotypes were detected in the environmental (sea ice plus seawater, or just seawater) samples. Diet phylotypes that were not detected in the environmental samples (8 in ISF-1, 2 in ISF-2, and 7 in
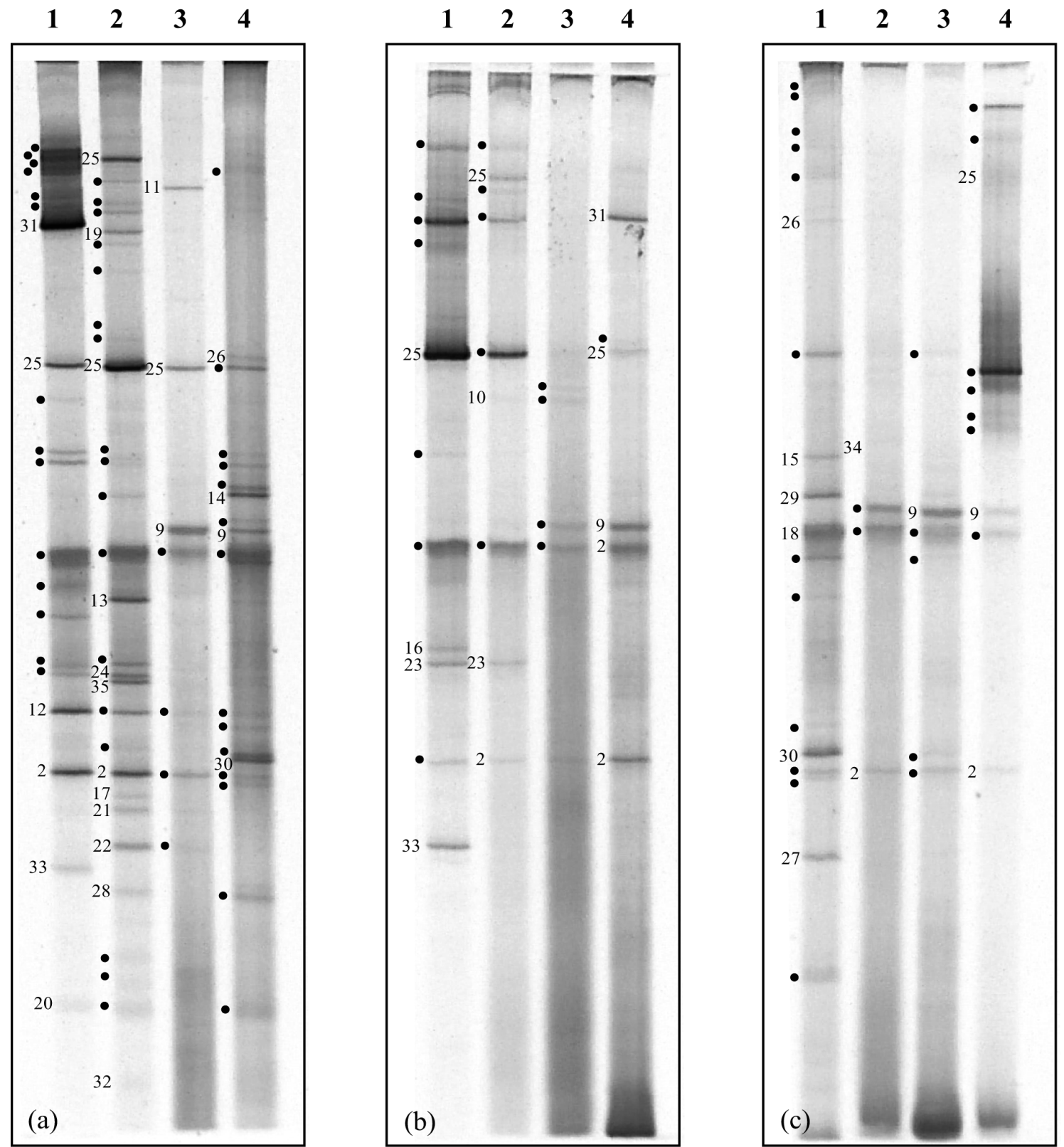

Fig. 2. DGGE images and sequenced phylotype results from in situ feeding (ISF) samples of Euphausia superba and their environment. Phylotype profiles reflect different environmental conditions from nearshore waters off Palmer Station, Antarctica, during austral spring 2002 on 3 occasions: (a) 3 November with sea ice cover (Lane 1: sea ice; 2: seawater; 3: krill fecal pellets; 4: krill gut contents), (b) 14 November with sea ice cover during peak spring bloom (Lane 1: sea ice; 2: seawater; 3: krill fecal pellets; 4: krill gut contents), and (c) 12 December in open water (Lane 1: seawater; 2: krill fecal pellets; 3: gut contents from 2 juvenile krill [total length $=19 \mathrm{~mm}$ ]; 4: gut contents from 1 adult krill [total length $=33 \mathrm{~mm}$ ]). Numbers are codes for bands excised and sequenced for phylotype analysis (see Table 1, Column 1). Dots indicate gel position of bands not sequenced 
Table 2. DGGE band image analyses from ISF samples of Euphausia superba and their environment. Percent matching bands $=100 \times($ no. of bands in common between diet and environment)/(total no. in diet or environment), followed by mean $( \pm$ SD) from the 3 sampling dates (ISF-1, $-2,-3=$ In Situ Feeding Periods 3 and 14 November and 12 December, respectively). ns: no sea ice in the region, open water only

\begin{tabular}{|lcccc|}
\hline Parameter & ISF-1 & ISF-2 & ISF-3 & Mean $( \pm \mathrm{SD})$ \\
\hline Phylotype richness & & & & \\
$\quad$ Sea ice & 20 & 11 & $\mathrm{~ns}$ & \\
$\quad$ Seawater & 29 & 9 & 18 & \\
$\quad$ Sea ice + seawater & 41 & 14 & $\mathrm{~ns}$ & \\
Fecal + gut & 19 & 7 & 13 & \\
$\quad$ Fecal + gut + sea ice + seawater & 49 & 16 & 25 & \\
Similarity Index $\left(C_{s}\right)$ & & & & \\
$\quad$ Sea ice and seawater & 0.33 & 0.60 & & \\
$\quad$ Gut and fecal & 0.35 & 0.44 & & \\
$\quad$ Juvenile gut and adult gut & & & 0.29 & \\
Percent matching bands & & & & \\
$\quad$ No. in common $\times$ total in environment & 26.8 & 35.7 & 33.3 & $31.9(4.6)$ \\
$\quad$ No. in common $\times$ total in diet & 57.9 & 71.4 & 46.2 & $58.5(12.6)$ \\
& & & & \\
\hline
\end{tabular}

ISF-3) probably represent organisms that were either below the detection limits $(\sim 1.5 \%$ abundance in sample), or were not present in those samples due to krill feeding in a patchy environment. Environmental richness was high (2-fold higher than diet samples), with an average of $32 \%(n=3, \mathrm{SD}=4.6)$ of the phylotypes detected being found in dietary components.

The use of a primer set targeting all eukaryotes, the approach applied in this study, differs from most studies employing PCR-based diet analyses, which often utilize highly specific primers designed to identify single species (Jarman et al. 2002, Symondson 2002, Nejstgaard et al. 2003), or group-specific primers (Höss et al. 1992, Jarman et al. 2004). The use of primers targeting all eukaryotes allowed us to (1) develop an approach inclusive of all potential prey, (2) develop a comparatively broad picture of the diversity in Euphausia superba's diet, and (3) avoid additional potential for PCR bias (see below) by conducting a single round of PCR. Efficiency, low cost and detailed phylogenetic resolution are desirable for comparative, multi-sample ecological studies, which is an advantage of this approach (Diez at al. 2001).

We identified 4 areas of consideration that are key to diet composition analysis: DNA extraction (recovery), uniform PCR amplification, sensitivity of detection, and unique sequence detection using DGGE. First, extraction or recovery of genomic DNA in proportion to amounts naturally occurring in ingested prey may be affected by differential digestion rates among prey types (e.g. faster in soft-bodied prey) or cellular differences influencing DNA extraction. In an attempt to minimize effects of digestion, we analyzed contents of the foregut, not the larger midgut of the krill, and targeted a rela- tively short ( 240 base) segment of DNA (Symondson 2002). However, results from our fecal pellet analyses may be biased toward poorly digested taxa, since diversity in the fecal samples was consistently lower than in the foregut, and 2 of the 4 sequenced phylotypes were affiliated with diatoms (AntEuk1324 and AntEuk13-107).

The second issue to consider is $18 \mathrm{~S}$ rRNA gene copy number, which can be highly variable among species of eukaryotes (Long \& Dawid 1980), resulting in unequal PCR amplification simply from differences in the relative copy numbers between different taxa rather than the mass of the organisms in the sample. Ribosomal gene copy number reflects the growth rates of the individual (Elser et al. 2000), and is often proportional to genome size (Prokopowich et al. 2003). This issue is a major challenge for PCRbased studies striving to quantify proportions of constituents in a mixed diet. In our study, the ribosomal gene copy numbers are unknown for most of the organisms that were detected, although they are inevitably different. Indeed, a recent study reported that rDNA copy numbers in phytoplankton can vary from 1 to $>12000$ copies (Zhu et al. 2005). Zhu et al. (2005) reported rDNA copy numbers for a few species related to phylotypes detected in our study (at least at the genus level: Thalassiosira sp., 400 copies; Nitzschia closterium, 100 copies; Bathycoccus prasinos, 10 copies). We are not aware that our survey was compromised by variation in the 18S rDNA gene copy number; however, we cannot rule this out at this time, and must emphasize that intensities of bands can vary for 2 reasons: (1) differences in rDNA copy number and (2) differences in organism abundance. We did detect a high number of different phylotypes, including 10 different phytoplankton in a single spring seawater sample (Fig. 2a, Lane 2), suggesting a relatively high sensitivity of detection.

Thirdly, as with any environmental PCR application, sensitivity of detection is influenced by the complexity of the target sequence population, primer design, and method of detection. Our results indicate that the eukaryote primer set was sensitive over a broad range of sample complexity (Figs. 1 \& 2) using a basic ethidium bromide stain for band detection. Previous studies have shown that sequences representing 1 to $1.5 \%$ of the population can be detected (Muyzer et al. 1993, Murray et al. 1996), limiting detection of rare sequences. This may explain the discrepancy observed of phylotypes detected in the diet that were not evident in the environment (17 of 39 diet phylotypes), and also 
suggests that krill selectively grazed these items. Although there is always the chance that we have missed elements of the prey population as a result of primer specificity, the wide range of taxonomic diversity detected is encouraging.

Lastly, DGGE has its limits when analyzing heterogeneous sequences found in natural populations. Originally developed for mutation detection in human chromosomal DNA (Fischer \& Lerman 1979), the complexity of natural populations can challenge the ability to discriminate between all different sequences. Confounding factors in which maximum resolution of different sequences is not achieved (reviewed by Muyzer \& Smalla 1998) can result in co-migrations of different sequences, causing difficulties in re-amplification and direct sequencing of the DNA. Also, sequences having more than 1 equally stable secondary structure, interspecies variation of rRNA genes (Dahllöf et al. 2000), double bands resulting from Taq error (Janse et al. 2004), or heteroduplex formation (bands resulting from annealing of 2 similar, yet slightly different sequences, e.g. Guldberg \& Guttler 1993) could result in $>1$ band per sequence. In our study, both of these conditions were observed, although the results are reproducible, (i.e. if one band co-migrates with another, or if the same sequence is found at 2 migration points, they will perform reproducibly in separate DGGE experiments). The absolute calculations of phylotype richness could then be compromised, as can the similarity calculations, although less so, particularly in the case of $>1$ band per sequence. Recovery of high quality se-

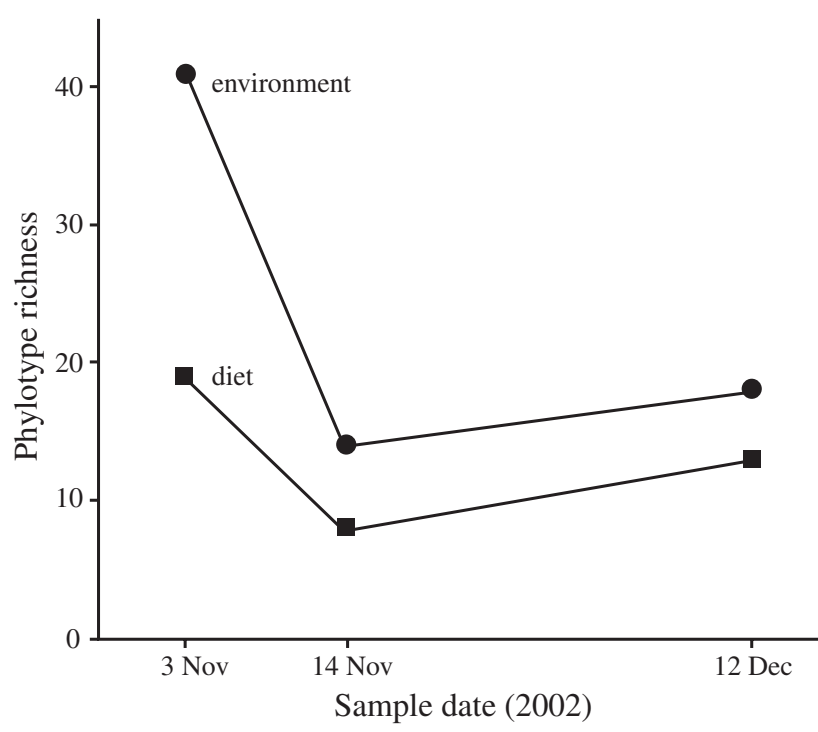

Fig. 3. Phylotype richness derived from DGGE band profiles for in situ feeding samples of Euphausia superba and their environment compared across sample dates. Environment samples (๑) include sea ice plus seawater, or just seawater; diet samples (ם) include fecal and gut samples quences was not achieved in all bands excised. This issue may be circumvented by cloning the DNA from excised bands (Fandino et al. 2001). Several phylotypes (AntEuk13-24, AntEuk13-5, AntEuk13-107 and [possibly] AntEuk16-8) were detected in $>1$ band. Ultimately, awareness of the issues influencing sequence detection is important, as is gaining a better understanding of the potential for the balance between copy number and cellular abundance. At present, PCRDGGE is not quantitative, but it does address many of the previous limitations concerning detection of the full complement of the diet population.

One clear advantage of this approach in comparison to other methods of diet analysis in a grazing zooplankter is that we detected several different heterotrophic taxa in addition to the predominant autotrophic taxa. Sequences detected in the krill diet fell into many eukaryotic taxa including diatoms (Bacillariophyta, the most prevalent group detected), dinoflagellates, cryptomonads, prasinophytes, ciliates, cercozoans, choanoflagellates, turbellarians, and possibly sponge larvae. Sponges are among the more common benthic invertebrates at our study site (Martin pers. obs.), and turbellarians can comprise $45 \%$ of the Antarctic sympagic meiofauna biomass (Schnack-Schiel et al. 2001). In the laboratory feeding trials, unexpected heterotrophic sequences such as the Umbraculum umbraculum-related sequence may have come from imperfect sorting of wild-caught copepods from other zooplankters, from copepod guts, or from internal parasites of the krill in the case of the putative apicomplexan sequence. However, the gut contents of heterotrophic prey are likely to be below detection limits, as prey DNA swamps the signal from their own gut contents. Note that because of the limits of detection, care must also be taken to avoid as much host DNA as possible, as evidenced by the krill bands in the first laboratory feeding trial, where the gut tissue itself probably masked the algal signal, given that they migrated to the same gel position. The laboratory trials also indicate that eukaryotic gut flora, if present, are largely below these detection limits.

Given the 3-fold range in phylotype richness of environment samples across dates, we also addressed whether such changes might be reflected in the krill diet. When compared, phylotype richness of the diet generally tracked changes in overall environment richness (Fig. 3). Comparisons of DGGE phylotype profiles also revealed that the sea ice microbial community and the surrounding seawater became more alike $\left(C_{S}=0.60\right.$, ISF2) as richness declined concomitant with sea ice melting and the associated phtyoplankton bloom. Although we did not compare phylotype profiles among dates, the different environmental samples (sea ice and seawater) compared within each date were more similar than samples in a comparable study (Gast et al. 2004). 
Many questions remain unanswered regarding the behavior and feeding ecology of Euphausia superba, particularly in reference to the winter feeding of larvae, and when and where omnivory plays an important role. Over a decade ago, several investigators (e.g. Smetacek et al. 1990) suggested that sea ice microbial communities might be an essential food resource for winter survival of larval and juvenile krill. Both behavioral and physiological evidence continues to support this concept (e.g. Frazer et al. 2002, Quetin et al. 2003). In our study, we hand-collected small swarms of larval krill actively feeding on sea ice surfaces with a well developed sea ice microbial community (ISF-1, -2), and thus it is interesting to note that the young krill analyzed appeared to be feeding on the sea ice microbial community given that food (inferred from chlorophyll a levels) was plentiful in the water column in the austral spring period sampled. A number of phylotypes in the sea ice were present in the diet samples, including the sequenced turbellarian band. It is unknown whether the heterotrophs consumed in this study were taken as by-catch or were selected for, but their detection suggests that this approach may assist in future investigations of omnivory in this species. Our results also reflect grazing studies in which krill were shown to select diatoms over prymnesiophytes (Haberman et al. 2003): Phaeocystis pouchetii was present in the sea ice microbial community but not in the diet (Fig. 2b, Band 16), while diatoms in general dominated the diet (Table 1, Fig. 2). Furthermore, differences between juvenile and adult gut samples in this study $\left(C_{S}=0.29\right.$, ISF-3) may be evidence of an ontogenetic or seasonal shift in feeding and/or habitat choice, and point to the utility of molecular dietary analysis in revealing behavioral attributes of E. superba. Although the numbers of samples studied here are limited, the data demonstrate that this technique can be used on individuals as well as pools of individuals to identify dietary constituents with fewer taxa-specific biases. In future studies it will be interesting to consider both variation in the diet between individuals and swarms feeding in different water masses or ice habitats.

In conclusion, there is a need to develop better methods to understand the diversity of organisms contributing to the diet of Euphausia superba, a key member of the Antarctic ecosystem, with the implications of such work extending well beyond this application. The PCRDGGE approach used in this study is a step in that direction, and proved useful not only in describing the diversity of eukaryotic micro- and nanoplankton under very different environmental conditions, but in linking changes in community composition to in situ changes in krill diet. Quantification of mixed-diet constituents is desirable in diet analyses, but quantitative approaches such as real-time PCR require a priori knowledge of the sequences to target. Thus, identification of putative diet components is a necessary first step, in which the approach described should be useful.

Acknowledgements. We thank R. Gast and S. Oakes for generously providing primers and algal cultures, respectively, A. Boettcher for reading early drafts of the manuscript, and M. Vernet, W. Kozlowski, K. Sines, L. Rogers, and M. Ferrera for providing the LTER cholorophyll a data. We are particularly thankful to have had C. Boch as a dive partner for the first author, for the assistance of E. Lindsey in the field and B. Carter in the laboratory, and for the exceptional support provided by the Palmer Station staff and dive tenders. This work was supported in part by grants from the National Science Foundation, Office of Polar Programs, Grant Nos. OPP0085435 to A.E.M., and OPP-0217282 to R.M.R. and L.B.Q.

\section{LITERATURE CITED}

Alonzo F, Nicol S, Virtue P, Nichols PD (2003) Lipids as trophic markers in Antarctic krill, I. Validation under controlled laboratory conditions. In: Huiskes AHL, Gieskes WWC, Rozema J, Schorno RML, van der Vies SM, Wolff WJ (eds) Antarctic biology in a global context. Backhuys, Leiden, p 121-128

Altschul SF, Madden TL, Schaffer AA, Zhang J, Zhang Z, Miller W, Lipman DJ (1997) Gapped BLAST and PSIBLAST: a new generation of protein database search programs. Nucleic Acids Res 25:217-221

Amann RI, Ludwig W, Schleifer KH (1995) Phylogenetic identification and in situ detection of individual microbial cells without cultivation. Microbiol Rev 59:143-169

Atkinson A, Snÿder R (1997) Krill-copepod interactions at South Georgia, Antarctica. I. Omnivory by Euphausia superba. Mar Ecol Prog Ser 160:63-76

Croxall J, Prince P, Reid K (1999) Diet, provisioning and productivity responses of marine predators to differences in availability of Antarctic krill. Mar Ecol Prog Ser 177: 115-131

Dahllöf I, Baillie H, Kjelleberg S (2000) rpoB-based microbial community analysis avoids limitations inherent in $16 \mathrm{~S}$ rRNA gene intraspecies heterogeneity. Appl Environ Microbiol 66:3376-3380

Díez B, Pedrós-Alió C, Marsh TL, Massana R (2001) Application of denaturing gradient gel electrophoresis (DGGE) to study the diversity of marine picoeukaryotic assemblages and comparison of DGGE with other molecular techniques. Appl Environ Microbiol 67:2942-2951

Elser JJ, Sterner RW, Gorokhova E, Faga WF and 6 others (2000) Biological stoichiometry from genes to ecosystems. Ecol Lett 3:540-550

Fandino LB, Riemann L, Steward GF, Long RA, Azam F (2001) Variations in bacterial community structure during a dinoflagellate bloom analyzed by DGGE and 16S rDNA sequencing. Aquat Microb Ecol 23:119-130

Fischer SG, Lerman LS (1979) Length-independent separation of DNA restriction fragments in two-dimensional gel electrophoresis. Cell 16:191-200

Frazer TK (1996) Stable isotope composition $\left(\delta^{13} \mathrm{C}\right.$ and $\left.\delta^{15} \mathrm{~N}\right)$ of larval krill, Euphausia superba, and two of its potential food sources in winter. J Plankton Res 18:1413-1426

Frazer TK, Quetin LB, Ross RM (2002) Energetic demands of larval krill, Euphausia superba, in winter. J Exp Mar Biol Ecol 277:157-171 
Gast RJ, Dennett MR, Caron DA (2004) Characterization of protistan assemblages in the Ross Sea, Antarctica by denaturing gradient gel electrophoresis. Appl Environ Microbiol 70:2028-2037

Guldberg P, Guttler F (1993) A simple method for identification of point mutations using denaturing gradient gel electrophoresis. Nucleic Acids Res 21:2261-2262

Haberman KL, Ross RM, Quetin LB, Vernet M, Nevitt GA, Kozlowski W (2002) Grazing by Antarctic krill Euphausia superba on Phaeocystis antarctica: an immunochemical approach. Mar Ecol Prog Ser 241:139-149

Haberman KL, Ross RM, Quetin LB (2003) Diet of the Antarctic krill (Euphausia superba Dana): II. Selective grazing in mixed phytoplankton assemblages. J Exp Mar Biol Ecol 283:97-113

Hopkins TL, Torres JJ (1989) Midwater food web in the vicinity of a marginal ice zone in the western Weddell Sea. Deep-Sea Res 36:543-560

Höss M, Kohn M, Pääbo S (1992) Excrement analysis by PCR. Nature 359:199

Janse I, Bok J, Zwart G (2004) A simple remedy against artifactual double bands in denaturing gradient gel electrophoresis. J Microbiol Methods 57:279-281

Jarman SN, Gales NJ, Tierney M, Gill PC, Elliott NG (2002) A DNA-based method for identification of krill species and its application to analysing the diet of marine vertebrate predators. Mol Ecol 11:2679-2690

Jarman SN, Deagle BE, Gales NJ (2004) Group-specific polymerase chain reaction for DNA-based analysis of species diversity and identity in dietary samples. Mol Ecol 13: 1313-1322

Kane MD, Poulsen LK, Stahl DA (1993) Monitoring the enrichment and isolation of sulfate-reducing bacteria by using oligonucleotide hybridization probes designed from environmentally derived 16S rRNA sequences. Appl Environ Microbiol 59:682-686

Lim EL, Amaral LA, Caron DA, DeLong EF (1993) Application of ribosomal RNA-based probes for observing marine nanoplanktonic protists. Appl Environ Microbiol 59: 1647-1655

Long EO, Dawid IB (1980) Repeated genes in eukaryotes. Annu Rev Biochem 49:727-764

López-Garcia P, Rodríquez-Valera F, Pedrós-Alió C, Moreira D (2001) Unexpected diversity of small eukaryotes in deep-sea Antarctic plankton. Nature 409:603-607

Magurran AE (1988) Ecological diversity and its measurement. Princeton University Press, Princeton, NJ

Massana R, Murray AE, Preston CM, DeLong EF (1997) Vertical distribution and phylogenetic characterization of marine planktonic Archaea in the Santa Barbara Channel. Appl Environ Microbiol 63:50-56

Moon-van der Staay SY, De Wachter R, Vaulot D (2001) Oceanic 18S rDNA sequences from picoplankton reveal unsuspected eukaryotic diversity. Nature 409:607-610

Murray AE, Hollibaugh JT, Orrego C (1996) Phylogenetic compositions of bacterioplankton from two California estuaries compared by denaturing gradient gel electrophoresis of 16S rDNA fragments. Appl Environ Microbiol 62:2676-2680

Muyzer G, Smalla K (1998) Application of denaturing gradient gel electrophoresis (DGGE) and temperature gradient gel electrophoresis (TGGE) in microbial ecology. Antonie Leeuwenhoek 73:127-141

Muyzer G, Wall ECD, Uitterlinden AG (1993) Profiling of complex microbial populations by denaturing gradient gel electrophoresis analysis of polymerase chain reaction- amplified genes coding for 16S rRNA. Appl Environ Microbiol 59:695-700

Nejstgaard JC, Frischer ME, Raule CL, Gruebel R, Kohlberg KE, Verity PG (2003) Molecular detection of algal prey in copepod guts and fecal pellets. Limnol Oceanogr Methods $1: 29-38$

Prokopowich CD, Gregory TR, Crease TJ (2003) The correlation between rDNA copy number and genome size in eukaryotes. Genome 46:48-50

Quetin LB, Ross RM, Frazer TK, Amsler MO, Wyatt-Evens C, Oakes SA (2003) Growth of larval krill, Euphausia super$b a$, in fall and winter west of the Antarctic Peninsula. Mar Biol 143:833-843

Regensbogenova M, Pristas P, Javorsky P, Moon-van der Staay CY and 4 others (2004) Assessment of ciliates in the sheep rumen by DGGE. Lett Appl Microbiol 39:144-147

Rosel PE, Kocher TD (2002) DNA-based identification of larval cod in stomach contents of predatory fishes. J Exp Mar Biol Ecol 267:75-88

Ross RM, Quetin LB, Lascara CM (1996) Distribution of Antarctic krill and dominant zooplankton west of the Antarctic peninsula. Antarct Res Ser 70:357-371

Ross RM, Quetin LB, Baker KS, Vernet M, Smith RC (2000) Growth limitation in young Euphausia superba under field conditions. Limnol Oceanogr 45:31-43

Ross RM, Quetin LB, Newberger T, Oakes SA (2004) Growth and behavior of larval krill (Euphausia superba) under the ice in late winter 2001 west of the Antarctic Peninsula. Deep-Sea Res II 51:2169-2184

Schnack-Schiel SB, Dieckmann GS, Gradinger R, Melnikov IA, Spindler M, Thomas DN (2001) Meiofauna in sea ice of the Weddell Sea (Antarctica). Polar Biol 24:724-728

Simpson JM, McCracken VJ, White BA, Gaskins HR, Mackie RI (1999) Application of denaturant gradient gel electrophoresis for the analysis of the porcine gastrointestinal microbiota. J Microbiol Methods 36:167-179

Smetacek V, Scharek R, Nothig EM (1990) Seasonal and regional variation in the pelagial and its relationship to the life history cycle of krill. In: Kerry KR, Hempel G (eds) Antarctic ecosystems: ecological change and conservation. Springer-Verlag, Berlin, p 103-114

Sogin ML, Gunderson JH (1987) Structural diversity of eukaryotic small subunit ribosomal RNAs. Ann NY Acad Sci 503:125-139

Symondson WOC (2002) Molecular identification of prey in predator diets. Mol Ecol 11:627-641

van Hannen EJ, Agterveld $\mathrm{MPv}$, Gons HJ, Laanbroek JJ (1998) Revealing eukaryotic genetic diversity in aquatic environments by denaturing gradient gel electrophoresis. J Phycol 34:206-213

Walsh JJ, Dieterle DA, Lenes J (2001) A numerical analysis of carbon dynamics of the Southern Ocean phytoplankton community: the roles of light and grazing in effecting both sequestration of atmospheric $\mathrm{CO}_{2}$ and food availability to larval krill. Deep-Sea Res I 48:1-48

Weisburg WG, Barns SM, Pelletier DA, Lane DJ (1991) 16S ribosomal DNA amplification for phylogenetic study. J Bacteriol 173:697-703

Zaidi RH, Jaal Z, Hawkes NJ, Hemingway J, Symondson WOC (1999) Can multiple-copy sequences of prey be detected amongst the gut contents of invertebrate predators? Mol Ecol 8:2081-2087

Zhu F, Massana R, Not F, Marie D, Valout D (2005) Mapping of picoeucaryotes in marine ecosystems with quantitative PCR of the 18S rRNA gene. FEMS Microbiol Ecol 52: $79-82$

Submitted: June 22, 2005; Accepted: December 30, 2005

Proofs received from author(s): August 8, 2006 